\title{
FIGURAS COREOGRÁFICAS DO CORPO
}

Cristina Lindenmeyer

Cristina Lindenmeyer

Universidade

Paris VII Diderot, Centro de Pesquisa em Psicanálise, Medicina e Sociedade, Paris, França. Membro da Associação Universitária de Pesquisas em

Psicopatologia Fundamental, Paris, França.
RESUMO: Propõe-se uma pequena incursão epistemológica com engajamento na releitura do estatuto do corpo na psicanálise freudiana, bem como de outros autores interessados nos conflitos que emergem a partir de manifestações somáticas. De todas as suas declinações, a que guardarei aqui e à qual adicionarei outras reflexões é o engajamento do corpo como lugar do corpo a corpo inicial com o outro. O corpo e os movimentos de dentro e de fora que o animam determinam a instauração da sexualidade psíquica e da conflitualidade inconsciente que a ele se associam. Ser-me-ia possível, portanto, pensaro corpocomo um lugarquenãoésomente o limite que separa, mas que também abre e coloca o sujeito em contato com fantasmas insuspeitos.

Palavras-chave: Corpo, psicanálise, coreografia, câncer.

ABSTRACT: Choreographic figures of the body. This work proposes a short epistemological journey and a different interpretation of body status within Freudian psychoanalyses, as with other authors interested in emerging conflicts initiated by somatic manifestations. From all potential ideas, I will maintain and build upon the body engagement as the initial place of body-to-body with the other. The body and its different internal and external movements constitute the settlement and the association of psychic sexuality and of unconscious conflict. Therefore, we must think of the body not only as the limit, which separates, but also that which opens and gives the possibility to get in contact with unsuspected phantasms of the patient.

Keywords: Body, psychoanalysis, choreography, cancer.

DOI - http://dx.doi.org/10.1590/S1516-14982016003008 
$\mathrm{H}$ elena, uma mulher com um corpo muito frágil e cuidadosamente vestida vem me ver sob a recomendação de seu médico oncologista. Seu discurso e postura demonstram certo controle sobre sua situação de doente. Somente seu olhar parece escapar a esse movimento. De minha parte, fico cativa a este contorno desesperado. Ela me diz que vem me ver para tentar compreender o que lhe aconteceu. Ela, que era uma mulher ativa, com uma vida plena, agora não possui mais o desejo de ver ninguém. Ela tem medo, medo de morrer deste câncer que não a deixa.

Deseja por vezes que tudo isso se acabe de uma vez por todas... logo ela que pensava que uma coisa dessas jamais pudesse lhe acontecer. Mulher bemsucedida profissionalmente, num casamento com dois filhos, levava uma vida onde tudo parecia encaminhar-se para o melhor. Agora, impossível de livrar-se dessa sensação estranha de não ser mais a mesma, com a morte à espreita, seus pensamentos a conduzem a sentimentos vertiginosos, tudo vacila ao seu redor. O que vai ser de seus filhos, de seu marido e de tudo aquilo que ela construiu? Estranha sensação de uma queda que não parece terminar. Num repente, ela me diz: “Eu apenas tornei-me terrivelmente humana!”. Terrivelmente humana era a expressão utilizada por Helena para descrever sua parte sombria e cruelmente desesperada que tentava deixar de lado e fugir por meio de uma vida bem repleta. Com sua doença, essa partesombria retorna. Esse sentimento dedesesperança, conhecido em seu passado e associado por ela a seu meio familiar complicado, retorna. Essa mesma desesperança que tinge seu olhar e que invade o espaço da sessão.

Aefraçãopsíquica experimentada porHelena,nomomentododesencadeamento de sua doença, apresenta-se como uma das figuras nas quais o corpo parece estar em aliança com a linguagem a fim de colocar em imagem os processos inconscientes. O corpo vem revelar o mais íntimo por meio de uma coreografia que, pelos gestos e figuras que ele compõe, pode desenhar no espaço da sessão o relato de toda uma vida.

'Coreografia', termo grego que significa 'compor figuras por meio de passos e gestos'. É escritura pelo corpo, escrever com seu corpo, escrever em deslocamento. Arte do dançarino por excelência, ou forma patológica que se mostra a nós na gestualidade repetitiva de alguns pacientes autistas. Duas formas opostas de utilizar o corpo.

Esse termo emprestado da dança vai nos permitir dar conta das situações nas quais o corpo invade o espaço até o ponto em que, em certas sessões, o analista é tocado no mais próximo de sua pessoa. Até o limite em que sua implicação torna-sefonte deinquietação, eporvezesmesmofontedemovimentosestranhos em seu próprio corpo. Tendo um corpo como espaço e a psiquê como parceira, a coreografia desenha a ação de uma escritura que se desloca no espaço e tempo. 
Coreografia, noção que sublinha o princípio do movimento que rege todas as operações psíquicas fora da consciência. Princípio do movimento que, como nos lembra Laurence Kahn em "A ação da forma" (2001, p.983-1.056), está presente em toda a obra freudiana. Princípio do movimento que pela sua presença recusa todo pensamento que poderia fixar-se religiosamente a um só movimento, a uma só interpretação.

Decerto é a partir dessa concepção de coreografia que, a meu ver, viria a capacidade do corpo, ou das figuras coreografadas pelo corpo, de se prestar a uma escuta metafórica em pleno espaço da sessão.

Coreografias do corpo, escrever com o corpo sem que, num primeiro momento, o verbo tome parte. É precisamente a partir dessa ideia de um corpo que zomba da anatomia e que se presta a colocar em cena as contradições psíquicas apontadas por Freud quando fala a propósito do encontro das manifestações somáticas em suas pacientes histéricas.

Ao longo de sua obra, o corpo toma formas diversas: o corpo na conversão histérica, o corpo erógeno, o corpo pulsional, o corpo do narcisismo, ou o Eu corporal, testemunhando assim sua função central na elaboração do aparelho psíquico. Em todas essas figuras, o corpo guarda uma coreografia que evolui ao longo da elaboração teórica. Sem sombra de dúvida, o corpo possui seu lugar na teorização freudiana.

De todas as suas acepções, a que guardarei aqui e à qual adicionarei outras reflexões é o engajamento do corpo como lugar do corpo a corpo inicial com o outro. O corpo e os movimentos de dentro e de fora que o animam determinam a instauração da sexualidade psíquica e da conflitualidade inconsciente que a ele se associam. Ser-me-ia possível, portanto, pensar o corpo como um lugar que não é apenas o limite que separa, mas também que abre e coloca o sujeito em contato com fantasmas insuspeitos.

Énessesentidoqueutilizareiaideia docorpocomoespaço de uma coreografia, lugar que permite o enlace, assim como o desenlace da montagem pulsional.

No seio da teorização psicanalítica o corpo foi objeto de numerosos debatese elaborações teóricas. Hoje, percebo uma confusão terminológica para dar conta do que chamamos 'corpo' na teorização freudiana. Muitas vezes eleécompreendido por meio de noções como: imagem do corpo, imagem inconsciente do corpo, o eu-pele, pacientes psicossomáticos, manifestações psicossomáticas, ou fenômenos psicossomáticos, o que vem ainda corroborar para uma inflação de noções que nos distanciam da proposta psicanalítica sobre o corpo. Esta confusão não data de hoje. No seio da teorização psicanalítica o corpo foi objeto de numerosos debates e elaborações teóricas. No congresso de psicanalistas de 
língua francesa de 2010, esses antigos debates ressurgiram. ${ }^{1}$ Retomarei apenas a discussão entre Freud e Groddeck, na qual Freud mostra claramente sua posição frente à questão: Existiria uma psicologia própria às doenças somáticas?

Numa carta muito curiosa endereçada a Freud (FREUD apud GRODDECK, 1977), Groddeck apresenta sua proposta frente aos males corporais. Ficamos surpresos pela forma como o segundo se dirige ao "caro professor". Como se acerca do campo das manifestações corporais, como se tratasse de um território desconhecido por Freud. Ora, desde "Ensaio sobre a histeria" (FREUD \& J. BREUER, 1895/1996), Freud elaborava sua visão do aparelho psíquico a partir de manifestações corporais. Ou seja, desde o nascer da psicanálise o corpo participava da sua elaboração. É interessante sublinhar a posição de recusa de Freud em relação à incursão de Groddeck. Em sua concepção do corpo Freud se afasta do domínio da biologia e coloca as manifestações somáticas na esfera intrapsíquica. Não é a doença que Ihe interessa e chama a atenção, mas como 0 corpo participa dos processos inconscientes presentes na formação do sintoma.

Groddeck com sua intenção de fazer dos dois, um, num apagamento à distinção corpo/psiquê (posição monista que será retomada pela teoria psicossomática), nos faria correr o risco de provocar um desaparecimento do essencial da montagem do processo psíquico inconsciente, "perdendo de vista" a ideia de um tratamento psíquico agindo num segundo plano (PONTALIS, 1988, p.157170). Segundo plano que representa para Freud toda uma dinâmica na qual o psiquismo se encontra imbricado nas situações de manifestações corporais. Podemos pensar que a objeção de Freud permite manter a presença do corpo em toda sua elaboração teórica.

Nos estudos sobre a histeria, sublinhamos uma referência plástica do corpo. No modelo da conversão histérica é a arte de dar forma ao interior que será constantemente evocada. Interior que na elaboração freudiana é sempre ligado à representação dos processos inconscientes. Desafiandoe subvertendo a anatomia, a histérica apoia-se sobre certas partes do corpo para construir outra cena. Coreografia inconsciente bem orquestrada pelos desejos interditos aos quais a histérica se entrega. Assim, a cena presente em seu corpo esconderia uma outra.

À questão de compreender como a histérica aproveita a ocasião dada pelo corpo para colocar em cena desejos interditos, Freud responde com a ideia de somatiches entgegenkomen, o que quer dizer "ir ao encontro de". O somático vai ao encontro de.

Quando existe uma excitação somática, seja ela normal ou patológica, apresenta-se a ocasião para que venham associar-se processos conflituais inconscientes insuspeitos até então. As partes do corpo de Elisabeth von R., Anna O, Dora, entre

\footnotetext{
${ }^{1}$ Ver Revue Française de Psychanalyse (2010), n.5, Entre Psyché et soma. Paris: PUF.
} 
outras, servirão como ocasiões dadas aos movimentos conflituais de encontrar um lugar de expressão. O afeto separado do representante da representação alcança a utilização da zona excitada e, assim, uma dinâmica fantasmática pode então instalar-se. Como conceber que o corpo possa engajar-se desta maneira? Eis a questão.

Arespostafreudiana passapelolugaratribuídoàinstauraçãoeaoengajamento da pulsão sexual. É sua presença no corpo a corpo inicial com o outro que lhe dá a possibilidade de tornar-se um local erógeno. Essas considerações encontrarão eco no trabalho sobre o narcisismo (FREUD, 1914/2005). A participação da regressão narcísica em situações de doença, permite a estes conteúdos arcaicos emergiremàcena:como senecessitassem deum sintoma orgânico, ummomento de ruptura, para que o fantasma pudesse advir. Exemplos clínicos não faltam para avaliar a importância de uma efração no corpo que desperta a necessidade de um 'Eu', solicitado em suas capacidades defensivas e criativas.

Ferenczi se apoiará sobre a ideia de um acontecimento somático ligado ao psíquico e proporá o termo "patoneurose" para pensar a importância psíquica de uma situação de doença. E toma como exemplo o dente cariado para falar de uma economia psíquica do sujeito em situações de dor provocadas por doenças ou lesões orgânicas. Em suas reflexões, a parte do corpo dolorida acolhe a partir da excitação da dor, toda uma trama fantasmática, que se aproveita da ocasião para se entregar aos movimentos inconscientes "insuspeitos".

Nesse exemplo do dente cariado, Ferenczi conduz as dores orgânicas em direção do deslocamento de uma experiência de prazer sob sua forma autoerótica. O dente cariado se transforma em órgão genital. Nesse movimento subversivo de ação do sexual, o sintoma orgânico não é apenas o estado de passividade. Em sua forma autoerótica ele passa também a um estado de atividade. É como se o sujeito que solicita o corpo ou que se apoia sobre ocasiões dadas pelo corpo, se reencontrasse com sua dinâmica pulsional e a reminiscência do encontro com o outro materno. Trata-se da potência da ancoragem sexual ligada a um corpo complacente até o limite de tornar-se outra coisa diferente do que a anatomia Ihe impõe. Uma cabeça, um olho, uma perna, uma barriga, uma boca podem ao mesmo tempo guardar sua função biológica, mas também ser outra coisa — esta outra coisa sendo sustentada pela ação da pulsão sexual e suas ligações com o objeto. ${ }^{2}$

Ocorpo sefaria presente para além de sua função biológica, pela ação do sexual nasecomas manifestações corporais queeleengendra.Nessemovimento em ação existe, em primeiro lugar, a importância do conceito de pulsão, para dar conta da dinâmica complexa na qual o psiquismo e o corpo se encontram imbricados.

\footnotetext{
${ }^{2}$ Ver adiante o fragmento do caso de Pietra.
} 
Assim o corpoé sublinhado como fonte, ao mesmo tempo que meio de descarga e de satisfação libidinal.Seu engajamento na construção psíquica através de suas partes utilizadas nas pulsões parciais, e em seguida o corpo inteiro, coloca-o nas cenas fantasmáticas e imaginárias mais diversas.

A partir da segunda tópica, a elaboração freudiana se desloca e "o Eu (este ser de fronteiras) é antes de tudo um Eu corporal" (FREUD, 1923, p.270). Com essa elaboração a instância do Eu nasce e se nutre de sensações corporais com o de dentro do corpo e o de fora que o atravessa. A dor tem papel essencial. $\mathrm{O}$ corpo não é apreendido numa ilusão de um corpo-função, nem numa ilusão de um corpo-imagem, como propõe a noção "imagem do corpo" de Schilder. Para Freud, ele é o lugar de inscrição das marcas presentes nas reminiscências das experiências precoces do infante, por onde o Eu poderá se constituir. Sendo assim, o lugar por onde emerge o pulsional, mas também o meio de chegar à sua satisfação, quer a mesma se dê no prazer ou no desprazer.

Com a noção de pulsão de morte na evolução da teoria freudiana, nós nos defrontamos com a função inconsciente mais promissora, mas igualmente a mais desconcertante. Via o masoquismo, o corpo encontrará um lugar e uma função no sofrimento.

Em "O problema econômico do masoquismo" (FREUD, 1985/1924), Freud evoca a doença como uma das três soluções para o psiquismo chegarà conclusão de um arranjo neurótico. A "necessidade de punição" ligada com "a incurável culpabilidade" (CHABERT, 2008, p.83-100) não irá ceder facilmente. Nessa proposição de Freud, a fachada muda, mas o prazer do sofrimento persiste sob a forma mais enigmática: agora ela é colocada numa parte do corpo, em sua face visível. Daí a frase de Freud: "o sujeito se sente doente e não culpado".

Felipe vem me encontrar após realizar mais uma vez um tratamento quimioterápico para câncer. Após seu primeiro tratamento tudo ia bem, muito bem talvez, até o dia em que de novo o médico lhe anuncia a presença de células cancerígenas.

Ao longo das primeiras sessões, ele me conta sua história sob a forma de um discurso sem fim, com uma voz monótona, que parecia querer me fazer dormir. Assim, será que ele queria me fazer sonhar em seu lugar? Parecia "me explicar" que ele não podia associar absolutamente nada sobre seu câncer.

Os silêncios obstinados das sessões e minha espera colocada à prova lhe permitem pouco a pouco a evocação desta lembrança repetitiva: "Quando pequeno eu estava na praia e me machuquei no joelho. Sangrei bastante, então minha mãe me levou a um lugar onde havia bombeiros com coisas de primeiros socorros. Havia seringas e produtos. Quando olho para fora, tinha um homem, que não era médico, um homem vestido com um uniforme de trabalho. Ele tinha uma serra. Quando ele passou por mim, me mostrou a serra e me disse: 'vou cortar teu joelho'." 
Em suas associações, um laço se estabeleceu entre essa lembrança e o fato de estar doente. Essa "complacência somática" permite compreender como o corpo pode servir de tela projetiva sobre a qual se revela a imagem do passado. Durante as sessões seguintes, Felipe irá revisitar diversas vezes essa lembrança que carrega os elementos que serão tratados por mim como "restos diurnos" no sonho. "Restos diurnos" que, como no sonho, funcionam também através de uma conivência com a linguagem: cortar o joelho é o ato castrador temido que um "homem, não um médico" poderia executar sobre seu corpo.

As sensações do corpo doente servirão de suporte ao surgimento das suas teorias sexuais infantis. Ele evoca então as relações com um corpo libidinal, pois a angústia de castração desencadeada o faz entrar numa atmosfera erótica.

Assim, Felipe acede a um corpo diferente que não é mais o corpo orgânico, mas um corpo "feito de história", historicizado e reconstruído a partir de "restos diurnos", onde se constroem as lembranças, "corpo arqueológico", poderíamos dizer.

A erotização do corpo, reencontrada por Felipe, pode tomar outras formas com outros pacientes. O componente autoerótico da sexualidade, necessário para o desenvolvimento psíquico de cada um de nós, pode em certos pacientes tomar outras vias para resolver seus conflitos internos. O trabalho analítico com mulheres que sofrem uma intervenção médica devido ao câncer dos ovários ou do útero, ou seja, dos órgãos sexuais femininos, me levou a pensar que estas pacientesvivemadoençanãoapenascomouma confrontaçãocomsuasangústias de morte, mas também como um ataque às suas identidades e capacidades sexuais. Uma paciente, após ter sofrido uma histerectomia, disse-me: "Acabou. Eles me retiraram tudo. Não tenho mais nada dentro de mim". Isto trouxe-Ihe outra pergunta: "Serei ainda uma mulher?" Como se à ameaça de morte acrescentasse a ela sentimentos de confusão em relação à sua identidade subjetiva e sexual, assim como às suas capacidades femininas.

Esta experiência clínica conduziu-me a pensar que estes cânceres, pela sua radicalidade, questionam as bases narcisistas do sujeito, e o complexo processo da construção da sexualidade feminina. Assim, sustento a hipótese de que a experiência da doença pode reatualizar movimentos psíquicos presentes na construção da psicossexualidade na menina. Sustento, ainda, que temores e inibições da sexualidade infantil reapareceriam no momento da experiência da doença. Por meio das construções psíquicas, reatualizadas pelos movimentos transferenciais, tentarei elaborar a ideia dos "tempos do feminino".

Como sabemos, a construção da psicossexualidade é um processo bastante complexo que não se limita à fase fálica. Deve-se levar em conta, também, as manifestações somáticas pré-genitais, assim como a importante função dos órgãos internos na construção da sexualidade na menina. 
Se, para alguns autores, as manifestações somáticas são tratadas como um déficit (proposta da teoria psicossomática), ou mesmo uma falha, na capacidade de simbolização, encontramos, em Joyce McDougall (1989), uma abordagem diferente. Ao invés de referir-se a um suposto ideal de normalidade para explicar as manifestações somáticas, a autora propõe a hipótese de uma linguagem arcaica, uma espécie de histeria primitiva, que ela chama de histeria arcaica. Tais manifestações tornar-se-ãoa via pelaqualopsiquismosedesvelarádandosentido a um sofrimento até então ignorado pelo sujeito.

Joyce McDougall ressalta que a distância que estes sujeitos parecem manter com seus mundos internos aponta um movimento defensivo de proteção e de sobrevivência psíquica. Trata-se de sujeitos que passaram, em suas mais precoces experiências, por situações nas quais o afeto fora asfixiado, e não encontraram outra solução para sobreviver psiquicamente a não ser através de manifestações não verbais e corporais. Diferentemente da histeria, na qual a sexualidade apoiase na organização edipiana, a ideia de histeria arcaica se refere ao mais primitivo direito de existir do sujeito, e às suas angústias ligadas a temores arcaicos.

Assim, o movimento regressivo próprio à situação de doença leva estes pacientes a reviverem lembranças e reminiscências de suas primeiras experiências objetais. Emalguns casos, as tribulações provadas ao longo do tratamento médico (ser transportado de um lugar ao outro, a febre, vômitos, a ameaça de vertigem) são experimentadas como revivescência de sensações corporais que traduzem experiências infantis arcaicas.

Partirei de uma situação clínica para ilustrar minhas hipóteses e mostrar, através do caso de Pietra, como a intervenção médica se confunde com um passado sexual infantil, reativado pela doença. Relatarei apenas dois momentos deste trabalho analítico que durou vários anos. Um primeiro momento, no qual a relação transferencial permitiu a transformação das queixas somáticas em produções psíquicas e, um segundo momento, no qual os sentimentos de ambivalência - amor e ódio - puderam emergir na situação analítica, sem ameaçar o equilíbrio narcísico de Pietra.

Trata-se de uma mulher de 40 anos que se submete outra veza um tratamento médico que consiste em uma série de sessões de quimioterapia, devido a uma recaída do seu câncer do ovário. Durante as primeiras sessões, ela me parece imersa em uma inércia que a impede de pensar, de poder pensar, inércia esta que chegava a contaminar nossos encontros. Todo o tempo da sessãoé utilizado para falar do seu câncer, da história da sua doença. Solicitava intensamente um olhar sobre este corpo que a traiu tornando-a doente, sem que ela mesma tenha percebidooaparecimentodocâncer, cujadescobertaocorreraduranteumexame de rotina ao ginecologista. 
Pietra inaugura seu discurso a partir das primeiras hospitalizações. No primeiro ano, ela se submete às sessões de quimioterapia necessárias para erradicar o câncer. Quando tudo parecia caminhar para o melhor, ela tem uma recaída. Em pânico com a ideia de que o câncer estaria de novo presente em seu corpo, decideprocurar outra equipemédica paratratarseu problema. Assimeladescreve esta fase: "eu não sentia nada, mas havia a palavra câncer". Incapaz de suportar a recaída, ela começa a tomar calmantes que parecem não agir sobre sua angústia. Por fim, a conselho médico, decide procurar-me para iniciar um trabalho analítico.

Mesmo motivada para o trabalho analítico, Pietra se mostrava paralisada, numa imobilidade psíquica que delineava as fronteiras do seu universo solitário. Durante as primeiras sessões, se queixava de uma sensação de indisposição depressiva provocada, de acordo com ela, pela descoberta do câncer. Ainda que apresentando uma capacidade pobre de fazer associações com sua história, ela continuava a vir às sessões com uma disciplina quase militar.

Após alguns encontros, Pietra irá abordar elementos do seu passado. É a segunda filha de uma família de quatro meninas. O pai trabalhava muito e sua mãe permanecia em casa, ocupando-se do lar e das filhas. Pietra casou-se aos 24 anos e teve dois meninos, coisa que muito surpreendeu sua mãe "quesó conseguiu ter filhas", me diz ela. Após sublinhar este "detalhe", que ficou marcado para mim, ela orientará sua fala sobre sua doença e os elementos que a cercam.

O que não se refere a seu corpo doente é completamente desinvestido. Sua única preocupação, manifestada de forma obsessiva, consistia em traduzir todo e qualquer sinal corporal como presença do câncer. A partir deste fundo hipocondríaco, Pietra passará seu tempo a mobilizar toda sua atenção sobre a melhor maneira de não mais "contaminar" ou "danificar" seu corpo. Este investimento hipocondríaco parecia funcionar como a procura de um lugar, e/ ou de um tempo, de experiência de si mesma, que se perdeu no momento do aparecimento do câncer.

Este movimento psíquico pode ser compreendido no mesmo sentido descrito por Freud no jogo do Fort-Da, no qual, através da sequência inaugurada pelo jogo, a criança faz a experiência de presença/ausência do outro materno, e pode experimentar o sentimento de permanência de si, sem o olhar constante e seguro da mãe (FREUD, 1996, p.2.850). É através desta identificação narcísica que o sujeito poderá se sentir habitando seu próprio corpo.

Minha prática clínica com alguns pacientes sugere a presença desta ameaça de suspensão de si mesmo (LINDENMEYER, 2007, p.157-165) no momento de experiência do câncer. Dessa forma, as reclamações hipocondríacas de Pietra referiam-se à construção de uma imagem do corpo que não a traísse. Foi assim que, passo a passo, se elaborava em mim a hipótese de que, ao falar o que sentia, Pietra me pedia, tal como uma criança à sua mãe onipotente, explicações sobre 
o que se passava em seu corpo. Por exemplo: "a senhora compreende, hoje vomitei toda a manhã”.

Nessa dinâmica transferencial, que continuou por vários meses, eu ocupava o lugar da figura materna capaz de acolher suas sensações corporais. As sessões eram assim vividas como a procura de um lugar, ou de um tempo, onde o sujeito poderia sentir-se sustentado. Por exemplo, Pietra continuava, de uma sessão a outra, como se não fosse necessário retomar o que tinha sido dito antes. Assim várias vezes, após a interrupção das férias, retomava as sessões continuando do que havia dito na sessão precedente, como se não tivesse ocorrido nenhuma ruptura; como se o sentimento de continuidade não pudesse ser perturbado. 0 que lhe importava era permanecer na ilusão de ser contida por completo pelo outro, sustentada pelo outro.

Sua vivência somática ajudou-me a compreender como o corpo poderia servir de suporte para a reatualização de histórias infantis. É sem dúvida por esta via que Pietra encontra a possibilidade de dar palavras ao seu sofrimento e de tornar-se ator de sua própria história. Assim, as queixas somáticas são utilizadas, no espaço das sessões, no mesmo diapasão dos restos diurnos no sonho. Mas se, aos poucos, Pietra pôde utilizar as sessões como meio para ter acesso ao material psíquico recalcado, outros elementos muito importantes irão aparecer.

Nos meses que se seguiram a este primeiro período, Pietra traz um sonho transferencial, no qual apareço, recebendo-a em um barco. Cito-o: "No sonho havia um barco e, por alguns dias, a senhora o aluga para mim e meu marido. Estava decorado como uma habitação, penso que a senhora não morava lá o tempo todo. Eu ia de uma peça à outra. Não recordo os detalhes." Ela me diz que, ao acordar, sentira-se bem. Logo após, entretanto, foi tomada por uma sensação esquisita e angustiante. Ela continua: "0 que eu pensei é que devo passar pela senhora para ficar melhor".

Fui investida, em suas associações, do papel materno, mas também como muIher potente que tem as chaves deste interior que representava este corpo-barco. A partir de suas associações no decorrer da sessão, a palavra 'barco' condensou a representação de uma imago maternal fálica e potente. Uma espécie de ideal de Eu reconhecido no exterior.

Ir no interior representava, para Pietra, ir à procura de atributos femininos queamãepossui, masqueos detém debaixo desetechaves.Sentimentoreativado pela intervenção médica. Este sonho parece-me representar o recalcamento da ambivalência dos sentimentos de amor e de ódio em relação à figura materna. A ambivalência, que deixou poucos vestígios no sonho, aparece nas sensações produzidas pelo sonho ao acordar.

Para a menina, a relação originária com a mãe é uma relação homossexual. Esta primeira fase marcará o início das várias etapas da construção da psicossexualidade. A reciprocidade desta relação, carregada de investimento libidinal, 
é essencial para a instauração de uma aliança narcisista. Esta relação primeira inscreve-se numa extrema proximidade corporal mãe/bebe.

O corpo do recém-nascido, através dos cuidados maternos, é sentido por este "casal" — o casal "mãe-criança" — como erotizado, excitante e excitado. Sabemos, desde Freud (1905/1987), que os cuidados maternos despertam a excitação, e colaboram com a integração psíquica do sujeito. Esta relação primeira, na qual a figura materna ocupa um lugar importante, constrói-se sobre o fundo da alteridade. Passará por um processo complexo, no qual a perda do objeto amado permitirá, no mesmo movimento, a instalação das identificações. Estas primeiras identificações - ser como - permitiriam à menina construir sua feminilidade.

Com efeito, as características da mãe são reconhecidas pela menina comotendo um estatuto mágico, que vai lhe permitir investir e afirmar sua feminilidade. Mas, se dificuldades contaminarem esta relação homossexual original, toda a construção da sexualidade será comprometida. Por exemplo, situações nas quais a menina não viverá sua feminilidade como algo oferecido por sua mãe, mas, antes, como algo dela roubado. Ou ainda, quando a mãeé percebida como frágil ao ponto de desfazer-se. Enfim, em todas as figuras nas quais a aliança narcisista não favorece os movimentos identificatórios, a consequência poderá ser não só a sufocação, mas também o obstáculo ao acesso à feminilidade.

As sessões seguintes de Pietra continuaram com as associações induzidas a partir do seu sonho e continuaram com as lembranças de sua infância quando se imaginava mal-amada e rejeitada pela mãe. Lembranças de menina que procurava o olhar da mãe, um gesto, enfim, algo que pudesse garantir-lhe o seu amor. A partir deste momento, o conteúdo das sessões alterava-se: as queixas somáticas atenuavam-se e davam lugar a outras associações e lembranças. Graças ao tecido transferencial que conseguimos instaurar e que funcionava como uma paraexcitação necessária para conter angústias arcaicas, outros elementos puderam aparecer.

Duranteassessões seguintes, Pietrafalava deseus desejos demenina, relativos à apreensão dos atributos femininos maternos, guardados com ciúme por uma mãe avara em demonstrações afetivas. Uma vez, disse-me: "Penso que a minha mãe sentia-se presa, porque não era contente, ela não gostava da vida no lar com as filhas. Além disso, teve apenas meninas. Mas, em contrapartida, a casa estava sempre em ordem, sempre limpa. E devia-se respeitar isto". A esta representação de uma mãe castrada vem acrescentar-se outro aspecto. A preocupação de sua mãe com a ordem aparece, para Pietra, como que condensando a vontade de livrar-se de qualquer expressão erótica como se, aí, se pudesse encontrar apenas sujeira. Para Pietra, experimentar estas sensações tornava-se impossível porque se a ordem e a limpeza não reinassem como sua mãe havia revisto, tudo poderia desabar. Objetos e palavras deviam, por conse- 
guinte, ficar imobilizados no espaço da casa, de modo que qualquer movimento tornava-se ameaçador. Sua imobilidade psíquica era a maneira de conter seus impulsos que se obstinava a apagar, enquanto que, um outro comportamento seria deixar-se morrer. Todas as sensações do seu corpo doente entravam em ressonância com o que sentia e que qualificava como "defeito". Convencida da fragilidade materna e de seu poder de suscitar suas incapacidades, Pietra um dia disse: "Penso, às vezes, que seria preferível que eu morresse. Quando durmo, penso que seria melhor se não despertasse mais, assim estaria feito." Esta frase condensa representações múltiplas. Trata-se de um desejo de morte animado por uma forte culpabilidade mas, também, da rivalidade gerada por desejos mortíferos.

Explorando os movimentos edipianos ligados a conflitos pré-genitais e potencialmente ligados à relação mãe-filha da fase anal, Maria Torok, em seu texto A significação do desejo do pênis na mulher (1991, p.189-229) problematiza a tese freudiana sobre a sexualidade na menina de maneira interessante. De acordo com Freud, o desejo do pênis aparece como a fonte da sexualidade feminina. Assim, Freud inscreve o feminino no terreno da decepção de não ser do outro sexo. Maria Torok parece sair desta dimensão idealizada e problemática. Para ela, a fonte da sexualidade encontra-se no conflito psíquico experimentado pela menina em sua relação com a mãe durante a fase de controle do esfíncter anal. Para Maria Torok quando ocorre, a percepção da diferença dos sexos, a menina já tem a experiência da exploração do seu próprio corpo.Contudo, algo se passou de modo que a menina abandona esta parte tão importante do seu corpo em proveito de um objeto suposto ser inacessível e inexistente nela. Este "algo" é, de acordo com Maria Torok, a força do recalcamento para que sua relação com a figura materna seja preservada.

O verdadeiro desafio que se encontra escondido por trás do desejo do pênis é, para Maria Torok, o recalque inconsciente do ódio dirigido à figura materna. Para não perder o amor da mãe, a menina se submete às exigências de limpeza, características da fase anal, impostas pelo papel educativo da mãe, renunciando, assim, às satisfações eróticas anais. Os impulsos agressivos que emergem em consequência desta renúncia serão recalcados a fim de proteger este relacionamento com afigura materna. Recalcando seu próprio desejo, a menina se inscreve em um juramento de fidelidade à figura materna. Isto porque em sua fantasia ela se experimenta como sendo o único objeto de satisfação maternal.

Segundo Torok, com o controle esfincteriano e a aprendizagem da limpeza, todo o interior do corpo da menina cai sob o controle materno. Tudo se passa como se a mãe monopolizasse o interior do corpo da filha, interior que compreende também a vagina. É assim, de acordo com Maria Torok que, para evitar os conflitos, a menina recalca a existência da sua vagina e inibe suas possibilidades 
de prazer. Em situações em que a mãe é percebida como frágil e faltosa, a criança não constrói uma imagem infantil autônoma. No lugar disso, cria uma imagem materna vazia, insatisfeita e invejosa: o controle da criança é sua única satisfação. Efetivamente, para poder se desfazer do controle da figura materna anal, sem dúvidaénecessário poder contarcomo apoio da identificação ao pai, portadordo falo. Em suas fantasias Pietra se representa no desinteresse paterno, mas também na posição de doente ela se submete como sendo o objeto de controle materno.

A esta ideia acrescentam-se as elaborações de Ferenczi quando nos diz que o sujeito pode se posicionar como protetor, ainda que seja em detrimento dele mesmo, pois esta posição assegura-lhe o recalcamento da sua agressividade, e garante-lhe o amor do objeto investido (figura materna).

A partir de situações clínicas, Maria Torok constata que mulheres em contato com sensações de prazer caem em forte culpabilidade, devido à autonomia que o acesso ao prazer oferece, o que significa, para a menina, uma despossessão sádica da mãe. Qualquer sensação de prazer funciona como ato masturbatório, e é vivido como forma de separar-se da mãe.

No modelo da masturbação ocorre um desdobramento de si mesmo, o sujeito identifica-se, ao mesmo tempo, aos dois personagens da cena primitiva e realiza o acoplamento de maneira autárquica. Ao tocar-se à procura do prazer, o sujeito produz uma união dele com ele mesmo, semelhante à dos pais que são unidos pelo ato sexual. $\mathrm{O}$ acesso à sexualidade feminina passa pela construção fantasmática da cena primitiva e a representação dos pais em alternância passiva e ativa. Esta construção fantasmática dá à criança a liberdade de movimentar-se nestas duas posições num nível intrapsíquico. Quando os conflitos pré-genitais persistem, a possibilidade de separar-se da mãe e movimentar-se nestas duas posições (ativa e passiva) torna-se impossível para a criança. Assim, qualquer ato prazeroso é vivido como destruidor, o que provoca o retorno de fantasias mortíferas de retalhamento e de destruição.

Apoiando-me nesta hipótese, acredito que os fantasmas sustentados por estas significações aterrorizantes reaparecem na experiência do câncer, através dos órgãos que tocam o interior do corpo da mulher. A doença reatualizaria e permitiria que estas constelações internas preexistentes achassem um lugar de expressão. Como se sentimentos arcaicos, mantidos secretos ao longo de toda a infância, tomassem uma dimensão mortífera, sacrificando a mulher por meio da doença. A doença é a cena arcaica que se torna visível no corpo da menina. Como se fosse necessário que algo do corpo seja sacrificado de modo a externar a violência do pulsional.

Os estragos produzidos no corpo da mulher permitem, assim, trazer à tona estas construções recalcadas da infância. Nesta dinâmica do sacrifício, o câncer toma o lugar do objeto odiado introjetado no sujeito. Assim, o sujeito mantém 
vivo o objeto materno através de ataques sádicos. O que me parece importante sublinhar é o componente sadomasoquista presente nesta dinâmica.

Para Pietra, o encontro com uma figura materna, reconhecida como insatisfeita e infeliz, a conduziu a movimentos psíquicos que a impediram de investir o prazer no seu próprio corpo. Da mesma forma, a ausência de trocas afetivas na relação com a mãe e com o pai, e vivida por Pietra como relações ameaçadoras, tornava impossível, e obstruía, toda mobilidade intrapsíquica. Assim, o câncer vem, portanto, funcionar tanto como lugar de projeção, como para denunciar sua sexualidade infantil.

Estas hipóteses encontram eco também nos trabalhos de Joyce McDougall (1989), quando ela nos relata manifestações somáticas oriundas da aliança com uma imago materna frágil, ainda que em detrimento de parte do corpo do sujeito. Qualquer tentativa de afastar-se desta relação arcaica, na qual o corpo será o sacrifício a pagar pela garantia da não contestação da potência materna, será vivida pela menina como um risco de desmoronamento psíquico.

Assim, o câncer de Pietra não éapenas a superfície que reflete algo, mas simo lugarde transformação do corpo para não ser confrontadaà imagem dovazio que o risco de perda de amor materno pode evocar. É precisamente neste espaço de transformaçãoe de metamorfose do corpo, que otrabalho com Pietra nos coloca.

A possibilidade de reintroduzir a dimensão pré-genital de sua sexualidade, a confronta com a ameaça de morte e com as infrações sexuais reatualizadas pela experiência do câncer. Este caso clínico parece-me ilustrar, pela reflexão que ele traz, os movimentos psíquicos mobilizados pela situação da doença e pela regressão induzida por esta situação, mas também como o corpo funciona como lugar de inscrição da memória dos vários tempos do feminino.

Estas reflexões aqui introduzidas nãoesgotam odebateem torno das questões corporais, mais pretende trazer uma contribuição que se alinhe às proposições freudianas dos "Estudos da histeria", quando o autor enfatiza os movimentos corporais em ligação com a linguagem.

Recebido em 2/12/2013. Aprovado em 7/6/2014. 


\section{REFERÊNCIAS}

CHABERT, C. (2008) La cruelle contrainte au bonheur. Libres cahiers pour la psychanalyse, n. 18. Paris: In press.

FREUD, S. (1977) "Lettre de Freud à Groddeck du 5 juin 1917", in GRODDECK, G. Le Ça et le Moi. Paris: Gallimard. . (1905/1987) Trois essais sur la théorie sexuelle. Trad. Fr. Paris: Gallimard.

. (1914/2005) Pour introduire le narcissisme, in La vie sexuelle, OCP. XII. Paris: PUF.

(1920/1996) "Au-delà du principe du plaisir", CEuvres Complètes XV. Trad. Fr. Paris: PUF. . (1923) Le Moi et le Ça. OCP, XVI. Paris PUF.

. (1924/1985) Le problème économique du masochisme. OCP, XVII. Paris: PUF.

. \& BREUER, J. (1895/1996) Etudes dur l'hystérie. Paris: PUF.

KAHN, L. (2001) L'action de la forme. R. F. P., La figurabilité, n.4. Paris: PUF. LINDENMEYER, C. (2007) "Etre en suspens", in Cliniques méditerranéennes, n.76.

MCDOUGALL, J. (1989) Théâtres du corps. Paris: Gallimard.

PONTALIS, J.-B. (1988) "Entre Groddeck et Freud", in Perdre de vue. Paris: Gallimard.

REVUE FRANÇAISE DE PSYCHANALYSE (2010) n. 5, Entre Psyché et soma. Paris: PUF.

TOROK, M. (1991) "La signification de l' envie du pénis chez la femme", in CHASSEGUET-SMIRGEL, J. (dir.) La sexualité féminine. Paris: Payot.

Cristina Lindenmeyer

cristina.lindenmeyer@wanadoo.fr 
